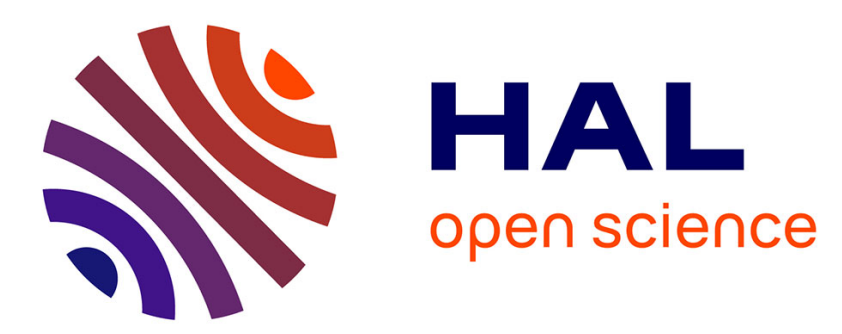

\title{
Estimation of energy fluxes and photosynthesis from thermal infrared, spectral reflectances, microwave data and SVAT modeling
}

\author{
Albert Olioso, H. Chauki, Jean-Pierre Wigneron, Patrick Bertuzzi
}

\section{- To cite this version:}

Albert Olioso, H. Chauki, Jean-Pierre Wigneron, Patrick Bertuzzi. Estimation of energy fluxes and photosynthesis from thermal infrared, spectral reflectances, microwave data and SVAT modeling. IGARSS'98, Jul 1998, Seattle, United States. hal-02769903

\section{HAL Id: hal-02769903 \\ https://hal.inrae.fr/hal-02769903}

Submitted on 4 Jun 2020

HAL is a multi-disciplinary open access archive for the deposit and dissemination of scientific research documents, whether they are published or not. The documents may come from teaching and research institutions in France or abroad, or from public or private research centers.
L'archive ouverte pluridisciplinaire HAL, est destinée au dépôt et à la diffusion de documents scientifiques de niveau recherche, publiés ou non, émanant des établissements d'enseignement et de recherche français ou étrangers, des laboratoires publics ou privés. 


\title{
Estimation of energy fluxes and photosynthesis from thermal infrared, spectral reflectances, microwave data and SVAT modeling
}

\author{
Albert OLIOSO, Habiba CHAUKI, Jean-Pierre WIGNERON \\ INRA Bioclimatologie, Domaine Saint-Paul, F-84914 Avignon Cedex 9, FRANCE \\ tel: 33-4-90 3164 99; fax: 33-4-90 3164 20; Email: olioso@avignon.inra.fr \\ and Patrick BERTUZZI \\ INRA, Station de Science du Sol, Avignon, FRANCE
}

\begin{abstract}
Soil Vegetation Atmosphere Transfer (SVAT) models have been implemented to simulate energy and mass fluxes between soil, vegetation and atmosphere of various ecosystems. Usually, these models are simple, but they use realistic descriptions of radiative, turbulent and water transfers. These include description of stomatal control of transpiration and $\mathrm{CO}_{2}$ fluxes. They can be used for assimilating remote sensing data and derive vegetation canopy evapotranspiration or photosynthesis ([1], [2], [3], [4], [5]). Various remote sensing data may provide useful information to drive SVAT models. Surface temperature may be used through inversion procedures to retrieve parameters related to stomatal conductance ([1], [3]) or root zone soil moisture ([2], [5]). Parameters related to vegetation structure ( $L A I$, vegetation height) may be retrieved from reflectance measurements in the solar domain, either through direct relationships with some vegetation index ([5], [2]) or by inverting radiative transfer formulation against spectral reflectance measurements ([1], [6]). Microwave data contribution has not been studied very often in the case of vegetation canopies, but they were proposed for estimating surface soil moisture ([7], [8]).
\end{abstract}

In this paper, inversions of the ALiBi model ([6],[9]) were performed to retrieve canopy evapotranspiration from thermal infrared, spectral reflectances and microwave data on two water stressed soybean crops. In a previous study ([3]), thermal infrared data alone were used to invert the model on plant water status parameters, while other parameters, related to canopy structure and soil surface water status, were prescribed from in situ measurements. In the present study, spectral reflectance and radar measurements were used to retrieve canopy structure parameters ( $L A I$ and vegetation height) and surface soil moisture by inverting radiative transfer models.

\section{Experimental data}

Two soybean field experiments were carried out in 1989 and 1990 at the INRA Research Center in Avignon ([6], [9]). The crops were grown from the beginning of July to the end of October (1989) and to the end of September (1990). In 1989, the crop received $233 \mathrm{~mm}$ of water and the starting soil water content was close to field capacity. The crop reached a maximum $L A I$ of 5.1. In 1990, the crop received $123 \mathrm{~mm}$ of water and the starting soil water content was field capacity. The crop reached a maximum $L A I$ value of 3.8. Energy balance fluxes, soil and vegetation parameters (soil moisture, soil water potential, $L A I$, canopy height, crop biomass, rooting depth, soil and leaf optical properties) were collected throughout both crop cycles. In 1990, more detailed measurements on vegetation included physiological characteristics (stomatal conductance, leaf water potential, leaf and canopy photosynthesis). Incident radiations, air temperature, vapour pressure, and wind speed were recorded above the canopy. Infrared brightness temperatures were continuously measured using thermal radiometers $(8-14 \mu \mathrm{m})$ in vertical viewing. Canopy reflectances were measured using reflectometers, in vertical viewing, at solar noon every three or four days, in the three wavebands of the SPOTHRV radiometer (green, red and near infrared). In 1989, active microwave measurements at C-band were also performed. Data were acquired by the scatterometer RAMSES (designed by CNES). Measurements were made every one or two days at $5.3 \mathrm{GHz}$ and incidence angles of $15^{\circ}$ and $23^{\circ}$.

\section{Description of the method}

The ALiBi model was described in details in [6] and [9]. The soil-plant-atmosphere system is splitted into two layers representing the soil surface and the vegetation above the ground. An energy balance equation is solved for each layer. Detailed parameterizations have been introduced to describe radiative transfers in the solar and the thermal infrared domains, turbulent transfers, stomatal control and water transfers. The transpiration flux from the vegetation layer to the atmosphere is expressed as a function of a vegetation surface conductance which depends on leaf stomatal conductances. The stomatal control is described, at leaf level, by a Jarvis-like equation as a function of incident light, leaf water potential, vegetation surface temperature and vapour pressure deficit. The water flux from the soil to the leaves, where transpiration occurs, depends 
on an hydraulic conductance $\left(G_{p}\right)$ and follows van den Honert's equation. The evaporation flux from the soil surface is expressed as a function of a soil surface conductance which depends on the soil moisture in the $0-5 \mathrm{~cm}$ layer $\left(\theta_{s}\right)$. Turbulent transfer parameterization uses classical diffusivity equations inside and above the canopy. Radiative transfers are based on the SAIL model which was developped by Verhoef ([10]) to compute canopy spectral reflectances. This model is coupled to the PROSPECT leaf model ([11]) which computes leaf optical properties from information on leaf structure and leaf water and chlorophyll content. The radiative transfer model in the microwave domain was described by [12]. It is a discrete first order radiative transfer model in which the vegetation is considered as a one-layer medium including leaves (assimilated to circular discs), stems and petioles (assimilated to cylinders). All these elements are characterized in terms of dielectric constant, size, volumetric density and distribution of orientation. The direct contribution of soil to backscattering is related to surface soil moisture (using IEM modeling).

Remote sensing data were used to derive some of the model parameters using inversion procedures. The hydraulic conductance $G_{p}$ was retrieved from surface temperature measurements, the surface soil moisture $\theta_{s}$ from microwave data (when available) and vegetation structure parameters ( $L A I$ and vegetation height) from spectral reflectances. As the other model parameters had less effect on fiux estimations, they were given standard values. Forcing meteorological variables (incident radiations, wind speed, air temperature and humidity above the canopy at an hourly time step) were directly measured.

- The inversion of the ALiBi model was based on the fitting of surface temperatures, simulated by the model, to the remotely sensed data, through the adjustment of the hydraulic conductance $G_{p}$. Since the model explicitly describes the mechanisms regulating energy balance, and in particular stomatal regulation, only a few number of temperature measurements were required to derive the diumal course of fluxes: the temperature acquired once a day at solar noon was used. This was done for each day of measurement.

- The inversion of the canopy reflectance model was done over the whole temporal profile using the equation given in [13] to describe the time evolution of $L A I$. The parameters in this equation and the other parameters in the radiative transfer model (soil reflectances, leaf angle distribution, chlorophyll leaf content and a mesophyll structure parameter) were retrieved by comparing refiectance simulations in red and near infrared wavebands to measurements along both crop cycles. Estimation of canopy height was done by using an empirical relation with $L A I$, which was established on an independent dataset.

- The inversion of the microwave model was based on a table relating the radar simulations to the surface soil moisture and to the stage of development of the crop canopy. This was done for each day of measurement using backscattering coefficients at both incident angles.

\section{Inversion results}

Inversions were evaluated by comparing daily values of simulated fluxes to measurements. In order to evaluate the influence of canopy structure and surface soil moisture retrieval accuracy on flux estimations, we first considered that field measurements of these quantities may be used to drive the model in addition to thermal infrared data (as done in [3]). In a second time, other cases were considered: $-i) L A I,-i i) L A I$ and height $\left(h_{c}\right)$, -iii) $\theta_{s}$, or $\left.-i v\right) L A I, h_{c}$ and $\theta_{s}$ were estimated by inverting radiative transfer against reflectance and/or radar measurements.

Accuracy of parameter retrievals was: $\operatorname{RMSE}^{1}(1990)=0.74$, $\operatorname{RMSE}(1989)=0.75, \operatorname{Mres}^{2}(1989)=0.46$ and $\operatorname{Mres}(1990)=$ -0.31 for $L A I ; \operatorname{RMSE}(1989)=0.11 \mathrm{~m}, \operatorname{RMSE}(1990)=0.10 \mathrm{~m}$, $\operatorname{Mres}(1989)=0.06 \mathrm{~m}$ and $\operatorname{Mres}(1990)=0.03 \mathrm{~m}$ for $h_{c}$; $\operatorname{RMSE}(1989)=0.047 \mathrm{~m}^{3} \mathrm{~m}^{-3}$ and $\operatorname{Mres}(1989) \simeq 0$. for $\theta_{s}$.

Numerical evaluation of flux estimations are summarized in Table 1. In 1989, when all the remote sensing data were used, RMSE was around $1 \mathrm{~mm} \mathrm{~d}^{-1}$ for the whole experiment. An underestimation of $22 \mathrm{~mm}$ (out of $166 \mathrm{~mm}$ ) was obtained. Results were better when more parameters were derived from in situ measurements rather than from remote sensing data. The best results were obtained when only $G_{p}$ was estimated from remote sensing data. The results were slightly degradated when $L A I$ or $\theta_{s}$ were derived from remote sensing. When $h_{c}$ was introduced, a larger degradation occured.

A closer look to the results showed that evapotranspiration assessments were of lesser quality when the canopy was not fully developed (here, we considered that the canopy was fully developed when its $L A I$ was higher than 3): large RMSE and systematic underestimations occured. Conversely, the estimations were unbiased when the canopy was fully developed (overestimation of no more than $3 \mathrm{~mm}$ out of $92 \mathrm{~mm}$ and $2 \mathrm{~mm}$ out of $132 \mathrm{~mm}$ were obtained in 1989 and 1990, respectively).

\section{Discussion and conclusion}

Retrieval of evapotranspiration from remote sensing data was undertaken (let's note that the ALiBi model may also be used to estimate photosynthesis [3]). Good results were obtained for well-developed canopies. When canopy cover was low, the results were less satisfactory. Many factors may explain this behaviour: $-i$ ) parameterizations used in SVAT models, particularly to simulate turbulent and radiative fluxes, have been developed for homogeneous canopies and might not be valid at low $L A I$; - -ii) soil evaporation, which was significant only at low $L A I$, might be ill-simulated; -iii) errors in the estimation

\footnotetext{
${ }^{1}$ RMSE: Root Mean Square Error

${ }^{2}$ Mres: Mean of residuals
} 
Table 1: Numerical evaluation of inversion results: daily evapotranspiration. $\sum E T$ is the cumulated evapotranspiration for the investigated days. RMSE: Root Mean Square Error; Mres: Mean of residuals.

\begin{tabular}{|c|c|c|c|}
\hline 1990 & $\begin{array}{l}\text { full period } \\
52 \text { days }\end{array}$ & $\begin{array}{l}L A I<3 \\
22 \text { days }\end{array}$ & $\begin{array}{l}L A I>3 \\
30 \text { days }\end{array}$ \\
\hline$\sum E T$ & $232 \mathrm{~mm}$ & $100 \mathrm{~mm}$ & \\
\hline \multicolumn{4}{|c|}{ Inverted parameter: $G_{p}$} \\
\hline RMSE & $0.60 \mathrm{~mm} \mathrm{~d}^{-1}$ & $0.63 \mathrm{~mm} \mathrm{~d}^{-1}$ & $0.58 \mathrm{~mm} \mathrm{~d}^{-1}$ \\
\hline Mres & $-0.12 \mathrm{~mm} \mathrm{~d}^{-1}$ & $-0.38 \mathrm{~mm} \mathrm{~d}^{-1}$ & $0.08 \mathrm{~mm} \mathrm{~d}^{-1}$ \\
\hline \multicolumn{4}{|c|}{ Inverted parameter: $G_{p}$ and $L A I$} \\
\hline RMSE & $0.61 \mathrm{~mm} \mathrm{~d}^{-1}$ & $0.65 \mathrm{~mm} \mathrm{~d}^{-1}$ & $0.58 \mathrm{~mm} \mathrm{~d}^{-1}$ \\
\hline Mres & $-0.08 \mathrm{~mm} \mathrm{~d}^{-1}$ & $-0.29 \mathrm{~mm} \mathrm{~d}^{-1}$ & $0.07 \mathrm{~mm} \mathrm{~d}^{-1}$ \\
\hline \multicolumn{4}{|c|}{ Inverted parameter: $G_{p}, L A I$ and $h_{c}$} \\
\hline RMSE & $1.05 \mathrm{~mm} \mathrm{~d}^{-1}$ & $1.44 \mathrm{~mm} \mathrm{~d}^{-1}$ & $0.62 \mathrm{~mm} \mathrm{~d}^{-1}$ \\
\hline Mres & $-0.32 \mathrm{~mm} \mathrm{~d}^{-1}$ & $-0.81 \mathrm{~mm} \mathrm{~d}^{-1}$ & $0.05 \mathrm{~mm} \mathrm{~d}^{-1}$ \\
\hline \multirow[t]{2}{*}{1989} & full period & $L A I<3$ & $L A I>3$ \\
\hline & 41 days & 22 days & 19 days \\
\hline$\sum E T$ & $166 \mathrm{~mm}$ & $74 \mathrm{~mm}$ & $92 \mathrm{~mm}$ \\
\hline \multicolumn{4}{|c|}{ Inverted parameter: $G_{p}$} \\
\hline RMSE & $0.82 \mathrm{~mm} \mathrm{~d}^{-1}$ & $1.02 \mathrm{~mm} \mathrm{~d}^{-1}$ & $0.50 \mathrm{~mm} \mathrm{~d}^{-1}$ \\
\hline Mres & $-0.27 \mathrm{~mm} \mathrm{~d}^{-1}$ & $-0.59 \mathrm{~mm} \mathrm{~d}^{-1}$ & $0.11 \mathrm{~mm} \mathrm{~d}^{-1}$ \\
\hline \multicolumn{4}{|c|}{ Inverted parameter: $G_{p}$ and $L A I$} \\
\hline RMSE & $0.87 \mathrm{~mm} \mathrm{~d}^{-1}$ & $1.11 \mathrm{~mm} \mathrm{~d}^{-1}$ & $0.47 \mathrm{~mm} \mathrm{~d}^{-1}$ \\
\hline Mres & $-0.33 \mathrm{~mm} \mathrm{~d}^{-1}$ & $-0.76 \mathrm{~mm} \mathrm{~d}^{-1}$ & $0.16 \mathrm{~mm} \mathrm{~d}^{-1}$ \\
\hline \multicolumn{4}{|c|}{ Inverted parameter: $G_{p}, L A I$ and $h_{c}$} \\
\hline RMSE & $0.93 \mathrm{~mm} \mathrm{~d}^{-1}$ & $1.09 \mathrm{~mm} \mathrm{~d}^{-1}$ & $0.69 \mathrm{~mm} \mathrm{~d}^{-1}$ \\
\hline Mres & $-0.41 \mathrm{~mm} \mathrm{~d}^{-1}$ & $-0.71 \mathrm{~mm} \mathrm{~d}^{-1}$ & $-0.06 \mathrm{~mm} \mathrm{~d}^{-1}$ \\
\hline \multicolumn{4}{|c|}{ Inverted parameter: $G_{p}$ and $\theta_{s}$} \\
\hline RMSE & $0.89 \mathrm{~mm} \mathrm{~d}^{-1}$ & $1.06 \mathrm{~mm} \mathrm{~d}^{-1}$ & $0.63 \mathrm{~mm} \mathrm{~d}^{-1}$ \\
\hline Mres & $-0.39 \mathrm{~mm} \mathrm{~d}^{-1}$ & $-0.85 \mathrm{~mm} \mathrm{~d}^{-1}$ & $0.16 \mathrm{~mm} \mathrm{~d}^{-1}$ \\
\hline \multicolumn{4}{|c|}{ Inverted parameter: $G_{p}, L A I, h_{c}$ and $\theta_{s}$} \\
\hline RMSE & $0.99 \mathrm{~mm} \mathrm{~d}^{-1}$ & $1.14 \mathrm{~mm} \mathrm{~d}^{-1}$ & $0.78 \mathrm{~mm} \mathrm{~d}^{-1}$ \\
\hline Mres & $-0.54 \mathrm{~mm} \mathrm{~d}^{-1}$ & $-0.96 \mathrm{~mm} \mathrm{~d}^{-1}$ & $-0.05 \mathrm{~mm} \mathrm{~d}^{-1}$ \\
\hline
\end{tabular}

of $L A I, h_{c}$ and $\theta_{s}$ from remote sensing data might have a significant influence on flux estimations. It has been stated (see [4]) that parameterizations used for turbulent exchange coefficients in SVAT models are often in defaults at low $L A I$. This leads to wrong simulations of surface temperature, and then to miscalculations of fluxes through the inversion process.

A sensitivity analysis of the inversion process in [4] showed that an accurate knowledge of vegetation height was necessary to obtain good estimations of fluxes (this is another illustration of the influence of turbulent exchange coefficients on the inversion process). Other parameters, such as $L A I$ or $\theta_{s}$, had less significant effects and less accurate values might be used. The results in the present study displayed behaviours in agreement with this analysis: the introduction of vegetation height estimated from remote sensing deteriorated the accuracy of flux retrievals more significantly than $L A I$ or $\theta_{s}$.

\section{References}

[1] P.J. Camillo. Using one- and two-layer models for evaporation estimation with remotely sensed data. In Land Surface Evaporation. Measurement and Parameterization, pages 183-197, 1991. Springer-Verlag, New York.

[2] C. Ottlé and D. Vidal-Madjar. Assimilation of soil moisture inferred from infrared remote sensing in a hydrological model over the HAPEX-MOBILHY region. J. Hydrol., 158:241-264, 1994.

[3] A. Olioso, O. Taconet, and M. Ben Mehrez. Estimation of heat and mass fluxes from $\mathbb{R}$ brightness temperature. IEEE Trans. Geos. Rem. Sens., 34:1184-1190, 1996.

[4] A. Olioso, D. Courault, H. Chauki, and J.-P. Wigneron. Estimation de l'évapotranspiration et de la photosynthèse à l'aide de modèles TSVA et de la température de surface. In Proc. 7th Int. Symp. Physical Measurements and Signatures in Remote Sensing (Vol. 2), pages 841852, Courchevel, France, 1997. Balkema (Rotterdam, The Netherlands).

[5] G.J.R. Soer. Estimation of regional evapotranspiration and soil moisture conditions using remotely sensed crop surface temperature. Rem. Sens. Environ., 9:27-45, 1980.

[6] A. Olioso. Simulation des échanges d'énergie et de masse d'un couvert végétal, dans le but de relier la transpiration et la photosynthèse aux mesures de réflectance et de température de surface. Thèse de doctorat, Université Montpellier II, 1992.

[7] R. Ragab. Towards a continuous operational system to estimate the root-zone soil moisture from intermittent remotely sensed surface moisture. J. Hydrol., 173:1-25, 1995.

[8] J.-C. Calvet, J. Noilhan, and P. Bessemoulin. Retrieving the root-zone soil moisture from surface soil moisture or temperature estimates: a feasibility study based on field measurements. Submited, 1997.

[9] A. Olioso, T.N. Carlson, and N. Brisson. Simulation of diurnal transpiration and photosynthesis of a water stressed soybean crop. Agric. For. Meteor, 81:41-59, 1996.

[10] W. Verhoef. Light scattering by leaf layers with application to canopy reflectance modelling : the SAIL model. Rem. Sens. Environ., 16:125-141, 1984.

[11] S. Jacquemoud and F. Baret. PROSPECT: a model of leaf optical properties. Rem. Sens. Environ., 34:75-91, 1990.

[12] J.-P. Wigneron, P. Ferrazzoli, J.-C. Calvet, Y. Kerr, and P. Bertuzzi. Optimal configurations of microwave remote sensing sensors to monitor soil and vegetation. A model analysis. Submitted, 1998.

[13] F. Baret. Contribution au suivi radiométrique de cultures de céréales. Thèse de doctorat, Université Paris Sud, 1986. 